\title{
ICT \& Innovation: A Case of Integration in a Regional Construction Firm
}

Graham Brewer, (University of Newcastle, Australia)

Thayaparan Gajendran, (University of Newcastle, Australia)

Goran Runeson, (University of Western Sydney, Australia)

\begin{abstract}
Construction firms in regional areas face considerable challenges to their competitiveness. Logistics, availability of suitable personnel, unfamiliarity with trading partners, and the tyranny of distance conspire to obstruct profitable engagement beyond their local area. Electronic information and communication technology (ICT) such as web-based project management applications and other forms of collaborative data sharing have the potential to mitigate many of these obstacles, but have yet to gain widespread acceptance, particularly by smaller regional firms who question their cost effectiveness. The attitudes of decisionmakers and the impact of their decisions on intra- and inter-firm culture lie at the heart of ICT-mediated innovation. This paper presents a case study of a specialist subcontractor located in regional New South Wales and its involvement in a New Zealand project, whose competitiveness arose from using ICT to integrate its own supply chain. It also provided additional value by triggering collaboration and integration in the broader project team. The case reveals that these outcomes were symptomatic of the organisational culture of the subcontractor, and were achieved through a combination of leadership, collaboration, flexibility and pragmatism, redolent of dynamic capabilities.
\end{abstract}

Keywords: ICT, Project team, Culture, Innovation, Regional

\section{Introduction}

Project team management and particularly the integration of construction project design and building phases has been a feature of human endeavour. As projects become more complex, so do the number and type of participant organisations. Whilst the project team objective must necessarily be to complete the project to specification, in the required time, and to the target cost the commercial imperatives of the participant firms may be at variance with these objectives. A measure of fragmentation and conflict is therefore an inevitable outcome of such conditions.

Successive industry reviews (e.g. Egan, 1998) have suggested the desirability of adopting production management strategies that have previously proved successful in the manufacturing sector. Examples include strategic alliances between trading partners (Sakal, 2005), lean construction, and supply chain integration (Khalfan, Asad, \& McDermott, 2007). Whilst there have been reported instances of success following their use they have not been widely experienced, or copied. Various explanations have been advanced for this, and the absence of information integration is one such example (Atkin, 1999). It is therefore paradoxical that integrative ICT, which has the potential to assist firms in regional areas to compete with metropolitan firms especially where their innovative capacity relates to marketing a unique product or service (Rogers, 1998, p 11), is not more widely utilised.

Although such technologies exist and can be shown to function successfully at a local level, it is apparent that the construction industry as a whole lacks the technological capabilities and business process maturity to currently fully exploit them (Brewer \& Runeson, 2009). Localised successes are therefore innovative in nature whether that be through product or service innovation (Teece, 2010) and the product of decision-making by one or more firms that is conducive to integrated, collaborative business processes. The research reported in 
this paper sought to surface the attitudes, decision-making behaviours and cultural consequences in relation to ICT-mediated innovation at the twin levels of the firm and project. A local Newcastle firm identified by previous research as demonstrating sustainable competitive advantage through innovation was found to be highly active internationally both in terms of managing its own supply chain relationships, and its involvement in internationally located construction projects. This case study is therefore a tale of two supply chains. One of them is regionally based and international in scope, successfully integrated by the ICT at the core of its specialist subcontracting business. The other is the project team of which it was a member, which accreted around a conventionally procured project, in which ICT use was largely absent.

\section{Literature Review}

\section{The Decision to Innovate}

At its most fundamental, innovation theory suggests that the decision to innovate is fundamentally driven by the search for sustainable competitive advantage, whether it be through the development of new products and services (Heertje, 2006; $p$ 26) or through the adoption of products and services that are new to a particular firm (and therefore immitative from their perspective) (Manley \& McFallon, 2003). It follows that the decision not to innovate - despite the presence of products or services that have the potential to deliver high levels of profit - will be made on the basis of an unfavourable risk/return on investment analysis (Heertje, 2006; $p$ 11). Such decisions are often assumed to be made by homo economicus, on the basis of rational consideration of the economic alternatives in pursuit of maximal profits. In reality such business decisions are made by humans, often on the basis of incomplete knowledge of the "facts", influenced by prior experience and also frequently emotion, in a boundedly rational way (Simon, 1991). Business decisions made on the basis of bounded rationality are rarely optimal, instead resulting in "satisficing" solutions, outcomes that can be described as being "good enough".

A better understanding of the influences that shape the attitudes of potential innovators and adopters of innovation, and particularly the attitudinal traits (Venkatesh, Morris, Davis, \& Davis, 2003) of strategic decision makers who sanction and dictate their deployment within construction organisations would help innovation levels in the construction industry. However, the human dimension has been largely overlooked by construction industry researchers and policy-makers.

Describing the attitudinal traits or attitudinal profile of a particular population is a technique that is familiar to both market and academic researchers, across multiple fields and disciplines. However in each case the starting point has to be a pre-existing framework of reference such as Ajzen's (1991) model, or multidimensional attitude profiling (Gann \& Salter, 2000). Implicit in this is the understanding that a collection of decision-makers within a single project will necessarily develop a group culture, be that positive or negative.

\section{Developing a Culture for Innovation}

Organisational culture has been variously described as a "strong prescription for success" (Martin et al., 2004) and "an interpretation for better understanding" (Willmot, 2000). However in both cases the concept of "cultural analysis" has been mooted as an appropriate mechanism to allow its investigation.

Culture is an emergent feature of a group, which springs from the underlying assumptions and beliefs of its members about what they share in common, how the world operates and consequently, how they should relate to it. This shapes their attitudes and often their consequent behaviour. Schein (2004) defines culture as:

'a pattern of shared basic assumptions [beliefs] that was learned by a group as it solved its problems of external adoption and internal integration, that has worked well

Brewer, G et al (2013) 'ICT \& innovation: a case of integration in a regional construction firm', Australasian Journal of Construction Economics and Building, 13 (3) 24-36 
enough to be considered valid and, therefore, to be thought to new members as the correct way to perceive, think, and feel in relating to those problems' ( $p$ 17)

Group culture can manifest itself overtly through rituals and other behaviours, although often the most enduring cultural traits are embedded in the underlying beliefs held by its members (Schein, 2004; Rousseau, 1990). These beliefs can take one of two forms: espoused, and actual.

Espoused or claimed (beliefs) are usually those attributes that people want to be seen to possess, or believe they should demonstrate. By contrast actual beliefs are those made manifest through their unconscious behaviour. Literature (Schein, 2004) suggests that attempting to understand culture through surface level manifestations alone (e.g. overt behaviour) is unreliable. Schein (2004) recommends surfacing deeper psychological manifestations such as underlying assumptions or beliefs as a more reliable approach. Thereafter it is possible to observe "inconsistencies" or "conflicts" between overt behaviours indicative of claimed beliefs, and underlying beliefs.

The learning or transmission of cultural assumptions or beliefs from one person to another within a group is the way in which group cultures form, whether they form spontaneously (e.g. when a group is thrown together unexpectedly) or by design (e.g. through recruitment of like-minded staff). Various metaphors have been developed to explain the cultural development of groups, likening it to engineered control mechanisms (Archer, 2004), infection (Geertz, 1966), or evolution (Sperber, 1996): where the spread or promotion of cultural traits is not actively initiated or managed there has to be an alternative, naturalistic facilitation process, as in the latter two instances. In the context of this paper the development of project team culture and the cultural influence of the industry beyond the focal project are of central importance.

\section{ICT as an Innovation}

Many authorities regard the integration of ICT into construction industry supply chain activities as both desirable and imperative (e.g. Department of Trade and Industry, 2001). This runs counter to its cultural norms and project-centric structure. A conceptual supply chain model of the temporary organisations constructed to complete construction projects is therefore useful to analyse cultural influences on ICT use in this context. Such a model can be derived from concepts originated by the Industrial Networks School of supply chain management (Ford, 1997; Hakansson \& Johanson, 1992). Thus each organisation within the project consists of a network of interacting actors, resources, and activities, all of which are necessary in order for it to function. Crucially this can be scaled to the level of the project, which itself becomes an actant in the network. The model therefore posits that a project team accretes around a project rather than an individual actor (e.g. the client).

There are a number of ways in which individual project organisations can be influenced by each other, and that these are not always contractual. Indeed they may not be formally recognised at all, rather being the product of a network of informal contacts and communications (Wasserman \& Faust, 1994). It follows that whilst the adoption of ICT might facilitate the communication of ideas and information within a single project this is only one of a number of possible communication channels (Gajendran \& Brewer, 2007). In the context of the current research it is clear that the characteristics thus conceptualised have the capacity to impinge upon the formation of culture in relation to the adoption and use of ICT within a project setting, both in a positive and a negative way.

Brewer \& Runeson (2009) develops a model of innovation and attitude to explain the influences affecting the behaviour of decision-makers considering the innovative use of ICT across a temporary project organisation (TPO) in the construction industry. Using Ajzen's Theory of Planned Behaviour (1991) as the point of departure it acknowledges that the ideal 
decision ought to be to integrate ICT throughout the primary participant organisations in a particular TPO, with its ultimate expression in the adoption of web based communication combined with online access to a shared project information database.

The collective attitudes and behaviours of a group of people in large part serve to define their group culture (Schein, 2004). Culture has the ability to influence all areas and activities within organisations, and whilst these are usually thought of as being an individual firm, club or institution, cultural concepts can equally be applied to project teams. It has been observed that the culture of a construction project influences its level and quality of ICT uptake and integration.

Previous research identified the Critical Success Factors (CSFs) for integration of ICT as being: Organisational Commitment; Organisational Attitude to Communication; Rights and Duties of Organisations (in relation to ICT-mediated communications); Investment Drive, and; Risks related to ICT Usage (Brewer \& Gajendran, 2006). Subsequent cultural analysis of these revealed that the cultural values espoused by the industry were analogous to the desired cultural values for an optimised project environment, which in turn ought to facilitate ICT integration. Unfortunately in practice it has been found that very few real life project cultures fully reflect these cultural ideals, resulting in a wide disparity between the levels of ICT integration experienced by participants in different projects and at different levels within the project supply chain.

It follows that a comparison of the actual culture of a project with the espoused values of the individual participants provides a basis upon which to identify the issues that lead to suboptimal levels of ICT integration. The Cultural Analysis Framework for ICT integration proposed by Gajendran \& Brewer (2007) maps the actual cultural characteristics of the environment into which ICT is deployed, comparing it to the cultural stereotypes first identified in the CRC-CI (2006) study.

\section{ICT Innovation in a Regional Context}

The concept of a regional culture is familiar in contexts as varied as the arts, sociology, or sport, and it is not surprising that regional distinctiveness may be detected in the business cultures of firms (Davidsson, 1995). Such cultures may develop endogenously, in response to competitive desires, or be fostered exogenously as a consequence of regional development policy initiatives. Indeed their regional location itself may be the trigger to innovate in order to survive (Boekema, Morgan, Bakkers \& Rutten, 2000).

The competitiveness of regional firms is frequently theorised as leveraging technology to achieve innovation, where a business culture develops driven by 'capitalist market logic' (Moulaert \& Sekia, 2003; p289). This observation suggests that more complex forces may be at play during the cultural development of innovative firms in regional locations; these are likely to be firm-specific.

\section{ICT as a Facet of Dynamic Capability in a Regional Context}

The strategic management literature has long recognised the importance of a firm's collection of capabilities as the basis upon which its performance is built. It is equally acknowledged within construction management literature that the overwhelming majority of firms in the architectural, engineering and construction (AEC) sector are SMEs, whose business objectives are to "make a living" in the short term, as they usually lack the time, resources and skills to formulate strategic plans. Their business capabilities can therefore be described as ordinary, or "zero-level" (Winter, 2002).

The concept of dynamic capabilities was initially defined as a firm's ability to "integrate, build, and reconfigure internal and external competences to address rapidly changing 
environments" (Teece, Pisano \& Shuen, 1997; p 516). This approach emphasised the agility required to adapt to a dynamic operating environment, as a response to increasingly rapid changes in market tastes and requirements. Dynamic capabilities therefore reflected an organisation's ability to achieve new and innovative forms of competitive advantage given their current set of competencies, capabilities, and using their current market position as the point of departure in the planning process (Teece, Pisano \& Shuen, 1997; p 516). It logically follows that dynamic capabilities are those which extend the firm's capabilities beyond a zero-level position.

Defining the specific attributes of a firm, which in turn combine to become parts of its capabilities is complex. Commentators are agreed that dynamic capability is rooted in managerial and organisational processes and routines (Teece, Pisano \& Shuen, 1997; Teece \& Pisano, 1994; Winter, 2002; Teece, 2011). Striking the right combination of reflective organisational learning, positional awareness, and robust business processes is central to a firm's dynamic capabilities: it is not simply enough to brilliantly improvise in times of stress or opportunity (Winter, 2002; p 3).

The durability of a competitive advantage derived from a firm's dynamic capabilities is largely determined by the length of time it takes a firm's competitors to replicate or imitate its innovation. This in turn reflects earlier choices made by the firm in response to its perceived market position and consequent options: dynamic capabilities are therefore highly pathsdependent, and it is this path dependency that may secure competitive advantage over the longer term, given appropriate agility (Teece \& Pisano, 1994; p13).

Construction firms in remote and regional areas of Australia tend to be SMEs. Their physical distance from major metropolitan markets has traditionally imposed limits upon the size of the markets they could serve and therefore restricted their capacity to grow beyond a certain size. A key component in the latest dynamic capabilities research is the emphasis on technology, and particularly ICT as assets upon which capabilities can be built (Teece, 2010).

Reconceptualising businesses within the AEC sector as being essentially information-based could be critical in enabling regionally based firms to compete by providing new products and or services, and operating in non-traditional markets (Winter, 2000; p3). In order to achieve such outcomes firms would have to develop new dynamic capabilities based upon existing skill sets, and would likely require the development of a set of strategic business relationships based upon collaborative working with their supply chain partners (Teece, Pisano \& Shuen, 1997; p 520).

\section{Methodology}

The design of this research was based upon four principles:

- Firms in the AEC sectors would consider their adoption of ICT to be an innovation;

- This decision would be made by key decision-makers within these firms;

- Although the decision-makers would consider their decisions rational, they would in fact be acting in a boundedly rational way;

- In the context of a TPO, the decision-making behaviour of individuals would contribute to the formation of a group culture, and that there was therefore a direct connection between the deeply held beliefs of individuals, their attitudes and consequent decision-making behaviours, and the culture of the TPO as evinced through its actions. (Brewer \& Gajendran, 2012)

The design of research methods is shaped by a combination of theoretical and practical research considerations. These commence with consideration of ontology, what is believed 
to exist and its relationship to the existing body of knowledge. Thereafter epistemological considerations are addressed, by identifying the appropriate level of proof required to confirm or reject these beliefs. Methodology provides the framework within which to conceptualise a philosophically consistent method of collecting this proof, and the design of appropriate research methods become the tools with which this proof is generated (Livesey, 2003).

The foregoing considerations cannot be divorced from the researcher, which reflects their theoretical perspective (Livesey, 2003) and values (Burgess, 1982; Glaser and Strauss, 1967). They are also influenced by the reliability and validity of data collection (Strauss and Corbin, 1990), and the reliability/validity of data analysis/abstracts and methods (Morse and Richards, 2002). This study was concerned with knowing, by reconciling a wide range of individual experiences into a form that enabled readers to know the collective experience in a meaningful way.

Insofar as it is possible to truly know anything it was necessary to make pragmatic epistemological decisions to facilitate the process of knowing:

- Firstly, to identify the type of evidence that would generate an answer to the research question, and

- Secondly ensure this was sufficiently compelling to satisfy the intended audience.

On a practical level these considerations were reflected in the authors' commitment to multiple research methods, drawing on both qualitative and quantitative research paradigms.

The TPO was used as the unit of analysis. However its actions were observed through a phenomenological lens to reveal the decision-making behaviors of its individual members. This took the form of a case study protocol that collected three types of data.

- A quantitative survey instrument was administered to each case study participant: this was identical to the survey instrument used in the CRC for Construction Innovation project "Critical Success Factors for ICT Mediated Supply Chains" (Gajendran, Brewer \& Chen, 2005), and its use was intended to reveal the espoused values of each respondent.

- A map of supply chain relationships was co-constructed with each respondent, identifying the connections and nature of their relationship with others in the TPO: These were then subsequently cross-referenced, a unified map of relationships produced, and validated by the respondents themselves.

- Interviews were conducted with the case study participants. These were semistructured and in-depth, guided by thematic prompts whilst allowing respondents to raise new issues wherever necessary. The prompts themselves were designed to elicit the respondents opinions and experiences in relation to:

o their own firms history and posture in relation to ICT adoption;

o their own firms attitude to collaborative working with trading partners in project supply chains;

- rights and responsibilities within collaborative ICT environments;

- strategic expectations of ICT investments;

- leadership and "championing" of ICT at the intra-and inter-firm levels;

○ their firms business processes, technologies, and agility to exploit opportunity.

The case study was completed over 14 months during the construction phase of the project, the qualitative survey instrument being administered at the outset, with the results being compared to the values obtained in the CRC project (Gajendran, Brewer \& Chen, 2005). 
Five representatives from primary stakeholders in the TPO (head contractor, client's inhouse project manager, architect, steel fabricator, client's façade consultant) and three representatives from the façade supply chain (specialist subcontractor, steel fabricator, glass supplier) were interviewed during that period. The proprietor and engineering design manager of the facade specialist subcontractor were individually interviewed at the beginning of the case study, and once again at its conclusion.

\section{Case Study}

This project involved the design and construction of an iconic public building in Christchurch, New Zealand. The architect modelled the project in three dimensions using CAD. The main project supply network was defined by a conventional set of contracts/subcontracts, without the mandated use of collaborative ICT.

A key visual/physical component of the building was the "Sculpture Wall", a complex 3-D curved engineered facade. An international specialist engineered facade subcontractor was engaged, on the recommendation of the client's own engineer. The subcontractor's own supply network was distributed across many countries, including China, Australia, Dubai, and Germany. As a consequence it had developed agility based upon the use of ICT, particularly 3-D CAD, and had seen fit to "embed" members of its own staff within supplier organisations in order to ensure that they produced information that was compatible with the subcontractor's own design processes and quality assurance protocols.

The integration of the specialist subcontractor's designs and products with those of the base building had the potential to be problematic, since another subcontractor responsible for fabricating the support structure had no compatible ICT competence. Nevertheless the specialist subcontractor saw fit to provide documentation beyond their contractual obligation, and access to intellectual property and personnel, commercially sensitive nature, in order to facilitate prompt project completion. They received acknowledgement that this behaviour both resolved a potentially serious problem and created a positive change in the project team culture, but received no additional remuneration.

\section{Results}

Three sets of data were collected from the case study participants: questionnaire survey results; supply network relationship maps, and; interview transcripts.

The questionnaire administered to case study participants was identical in all respects to the one used for a national survey during the $\mathrm{CRC}-\mathrm{Cl}$ research project (2006), which identified six critical success factors for ICT innovation, differentiated by industry sector (clients, consultants, contractors and subcontractors). These were subsequently recognised to be analogous to the espoused values of ICT decision-makers in construction related professions, and consequently the questionnaire was used in this case study to reveal whether any of the participants espoused values that were at odds with their colleagues in the rest of the industry. It was found that all participants were found to hold views that were similar to others holding similar positions (i.e. within one standard deviation of the industry norms).

The second set of data was a series of supply network relationship maps that were constructed by each interviewee with the assistance of the interviewer. Each map detailed the interviewee's firm in relation to its immediate trading partners and those other project participants involved in the study. The nature of the relationships between these firms was detailed in terms of contractual, non-contractual, and monitored links, highlighting those that were considered by the mapmaker as being strategic in nature. The consolidated supply network relationships (subsequently reviewed and approved by all participants) are illustrated in Figure 1. 
The final set of data was the interview transcripts. These were analysed using the techniques described previously in the methodological section of this paper. This resulted in a table of thematic codes, the highest level of which coincided with the six critical success factors arising out of the $\mathrm{CRC}-\mathrm{Cl}$ research. Immediately beneath these were a series of themes derived from the open coding process, each of which was subsequently illuminated where appropriate using axial coding techniques. 12 interview transcripts, containing a total of over 135,000 words were coded, resulting in 162 raw codes. Table 1 shows a representative extract from the consolidated coding table, where rationalisation of the coding has reduced the total number of codes to 93 , and where alphabetisation has been performed in order to remove any connection to the original critical success factors.

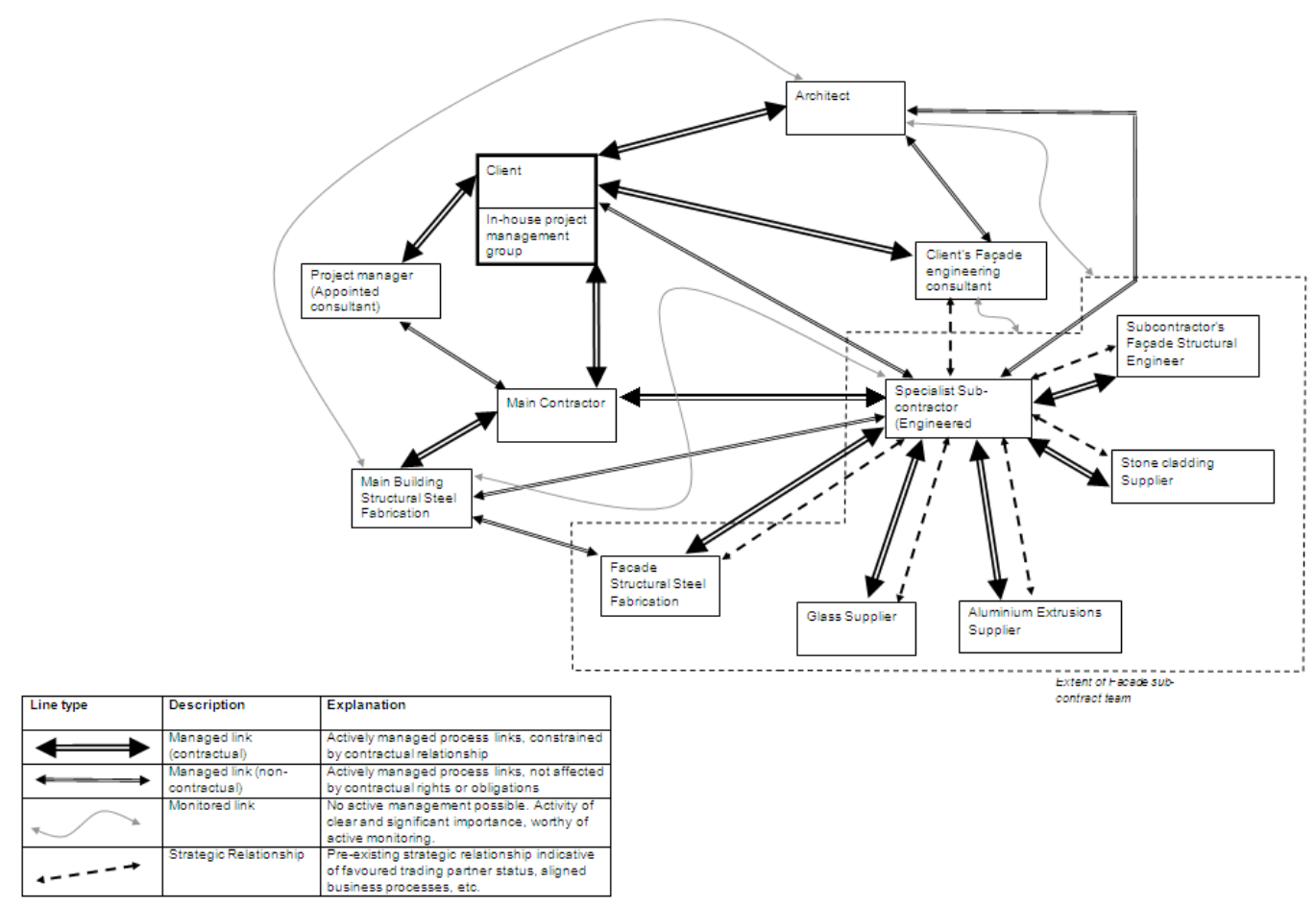

Figure 1 Consolidated supply network map

Given that the critical success factors were generalised to the entire industry, and that the detailed coding for the case study was intended to illustrate the specifics as to how these success factors found their expression in this particular case study project, it became apparent that there were in fact two stories to be told: one related to the TPO itself, as originally envisaged at the beginning of the research; the second story related to the specialist facade subcontractor and its upstream supply chain, which contrasted sharply with construction industry norms. Accordingly the data - and particularly the open/axial themes underlying the critical success factors - were reanalysed, this time placing the subcontractor (as opposed to the project) at the focus point, and using a Dynamic Capabilities lens. This enabled the researchers to drill down to the root causes of its success in innovating. It is important to note that whilst some of these were ICT-related, others were not, with issues such as leadership style, and organisational culture, agility, service innovation and process innovation all being found to contribute. It is also important to note that since no additional interview data was collected beyond that originally designed to investigate critical success factors, the dynamic capabilities analysis should be regarded as preliminary and exploratory, requiring further investigation to confirm or refute. 


\begin{tabular}{|c|c|c|c|}
\hline $\begin{array}{l}\text { Open codes } \\
\text { derived from first } \\
\text { pass analysis }\end{array}$ & Explanation & $\begin{array}{l}\text { Axial codes } \\
\text { derived from } \\
\text { subsequent pass } \\
\text { analysis }\end{array}$ & Explanation \\
\hline $\begin{array}{l}\text { relationships (long } \\
\text { term) }\end{array}$ & $\begin{array}{l}\text { The notion that firms may enter into } \\
\text { strategic business relationships that endure } \\
\text { over time. In this case, ICT compatibility } \\
\text { is seen as facilitating such relationships. } \\
\text { Reflects such issues as technology } \\
\text { compatibility, complimentary distinctive } \\
\text { competences, niche markets, etc. }\end{array}$ & $\begin{array}{l}\text { relationships } \\
\text { (quasi-strategic) }\end{array}$ & $\begin{array}{l}\text { A code group that acknowledges that enduring } \\
\text { business relationships often reflect expediency on the } \\
\text { part of one or more parties to the relationship. }\end{array}$ \\
\hline $\begin{array}{l}\text { revolutionary } \\
\text { change }\end{array}$ & The antithesis of incremental change. & & \\
\hline reward & The expected outcome of using ICT. & & \\
\hline $\begin{array}{l}\text { risk } \\
\text { risk (management) } \\
\text { risk } \\
\text { (minimisation) } \\
\text { risk (prediction) }\end{array}$ & $\begin{array}{l}\text { Codes reflecting both the risks associated } \\
\text { with adopting and using ICT within an } \\
\text { individual firm, and within a project team } \\
\text { for communication with other participants. }\end{array}$ & & \\
\hline $\begin{array}{l}\text { ROI } \\
R \$ I \text { (difficulty of } \\
\text { measuring, ICT } \\
\text { investments) } \\
\text { ROI (long term) } \\
\text { ROI (short term) }\end{array}$ & $\begin{array}{l}\text { Codes reflecting the expectation of } \\
\text { benefits accruing from the use of ICT, both } \\
\text { in the short term and long term. Short- } \\
\text { term has a specific meaning of ' within the } \\
\text { current project', whilst long-term extends } \\
\text { beyond a single project. Difficulties } \\
\text { associated with specifying precisely what } \\
\text { are and are not benefits, and how to } \\
\text { measure the non-financial benefits are } \\
\text { problematic. }\end{array}$ & ROI (personal) & $\begin{array}{l}\text { A major and significant code group that recognises } \\
\text { ROI existing on a number of different levels and over } \\
\text { a number of different time spans. A significant } \\
\text { addition is the recognition that individual users within } \\
\text { a firm expect to derive a return on their own } \\
\text { investment (usually of time and effort in learning new } \\
\text { systems) in relation to ICT, and whilst the initial } \\
\text { choice to adopt is usually determined from above, the } \\
\text { choice to engage wholeheartedly is largely a personal } \\
\text { one. }\end{array}$ \\
\hline
\end{tabular}

Table 1 Extract from consolidated code table

\section{Discussion}

The collaborative use of ICT across the TPO assembled to complete the design and construction of a construction project, is frequently held up as the future of project delivery. Its purported benefits include improved design coordination, lessened conflict, reduced communications costs and importantly, an accurate stream of information that can be used throughout the life of the constructed asset (Eastman, Teicholz, Sacks \& Liston, 2008). However all of this is dependent upon the presence of participant firms that share compatible technologies, business processes, and cultures, led by people who hold attitudes and display behaviours conducive to collaboration (Gajendran \& Brewer, 2007). In this case it was clearly apparent that the TPO did not possess these characteristics, whilst the specialist facade subcontractor's own supply chain did.

Experience has shown that it is unusual to find conditions conducive to ICT integration across an entire TPO, and this case was no exception. Nevertheless, it could be seen that where competitive conditions in the industry were suitable it was possible for stable supply chain relationships, based upon ICT infrastructure to develop and endure. Moreover it was observed that the presence of a project participant with experience in this regard enabled such collaborative behaviours to temporarily exist within the wider network of TPO members. The value of this phenomenon was not confined to the engineered facade either, "infecting" the operational culture of the project team, leading to a more collaborative working environment (Brewer \& Gajendran, 2012; p 8).

From the client's perspective the nature of the trigger to positive project outcomes was of no significance, though the outcomes themselves were. From the architect's perspective the behaviour of the specialist subcontractor was both admirable and enviable. Yet although the architect possessed comparable technology they did not see fit to champion its use within the project network, citing low expectations of technological compatibility with the project network partners. Ultimately the success of the specialist subcontractor's own supply network was fuelled by commercial expedience based upon proven ability to provide the required performance in terms of time, cost, and quality. Nurturing and maintaining this network was regarded as essential to sustaining competitive advantage. 


\begin{abstract}
"You know, there are 6 billion people in the world, and it's surprising how difficult it is to find one of them who will reliably supply you with what you need on a regular basis.... When you find someone you can do business with, you cling onto them. They are pure gold. They become family." (CEO, Specialist subcontractor).
\end{abstract}

This case study revealed a number of the paradoxes inherent in the industry at this time. Firstly, a number of the project participants had invested in BIM-capable technologies, and although each was satisfied with their use of it at an intra-firm level, the same could not be said for inter-firm information sharing. However none of these firms regarded this as an ICT failure, perhaps because none of them had genuinely BIM-ready business processes, which are inherently boundary-spanning, and require a degree of shared business processes. The specialist subcontractor came closest to this, however their supply network could not be said to be BIM-ready.

Secondly, for BIM integration to be successful it has to be championed by someone in the project supply network, ideally the client, or failing that the architect or head contractor. Their power position should allow them to mandate the use of a particular technology/protocol, thereafter requiring them to support its use, as they would be recipients of the benefits thus accrued. Disregarding the precise nature of BIM, the closest this condition came to existing within the case study project supply chain was where the specialist subcontractor championed the use of diverse ICT to facilitate a shared understanding of the technicalities of the Sculpture Wall. Moreover whilst this was confined to construction of a specific element of the structure, the collaborative effect it engendered pervaded other aspects of the project in a beneficial way, signposting the potential that this approach has when properly implemented.

Lastly, the beneficial effects of ICT-mediated collaboration on this project were realised in spite of the procurement mechanisms, not because of them. They arose because the specialist subcontractor was prepared to set aside the letter of the contract and pursue a more collaborative approach in order to achieve the project objective that was the sculpture wall. This required them to be exposed to what amounted to unregulated risk and unrewarded risk-taking, a behaviour that would be considered unusual in the construction industry. On the other hand, without such behaviour the project would almost certainly have taken a substantial turn for the worse. This highlights both the inadequacy of existing procurement mechanisms for suitability in the BIM age, and the necessity of developing new mechanisms to fill this gap, if BIM is to fulfil its potential.

It can be seen from the foregoing that the culture of the specialist subcontractor's firm performed a beneficial role by facilitating the effective completion of the Sculpture Wall, and this can be seen as a natural consequence of the pursuit of their own business interests. That they were able to see a clear business benefit in what could reasonably be seen as risky and apparently altruistic behaviour speaks to the nature of the firm itself. In particular it would seem to indicate a deep-seated confidence in the capabilities, both technological and interpersonal, of the firm to succeed in such an environment, which extended beyond brilliant improvisation in times of stress (Winter, 2002; p 3). As such it would seem reasonable to speculate that this behaviour was public manifestation of a dynamic capability that had been actively developed by the specialist subcontractor's management, and while exploring this concept was not originally an overt objective of this research the connection between deeply held beliefs and attitudes, subsequent decision-making behaviour, and the formation of project team culture certainly was. If one of the dynamic capabilities of the specialist subcontractor was perceived by its management to be to integrate, build, and reconfigure internal and external competencies to address rapidly changing environments (including project teams) (Teece, Pisano \& Shuen, 1997; p516) then this certainly would deserve further investigation. Moreover it would be important to understand the influence that the firm's regionality had played in this behaviour (Boekema, Morgan, Bakkers \& Rutten, 2000).

Brewer, G et al (2013) 'ICT \& innovation: a case of integration in a regional construction firm', Australasian Journal of Construction Economics and Building, 13 (3) 24-36 


\section{Conclusions}

The focal company in this case study shows to innovate in a number of different ways: firstly it shows two reconceptualising its product in terms of the information and intellectual property that it generated, rather than the constructed artefacts that resulted from its implementation; secondly, it recognised the need to form and maintain a number of stable relationships with the suppliers in its supply chain; thirdly, it understood that these would only deliver value to it if their business processes, and specifically the ICT that facilitated them achieved a high level of integration. It was apparent, given the diverse international locations of the focal company's supply chain partners and projects that their location was a critical trigger to the foregoing strategic decisions. It is less clear whether their regional location was itself a trigger to seeking overseas supply chain partners.

The level of strategically driven reflection and reconceptualisation undertaken by the senior management of the specialist subcontractor could be thought of as atypical for SMEs in the construction industry. Their recognition of the need to fully exploit the capabilities of ICT in order to integrate their supply chain placed their relationship management abilities at the heart of their business model, requiring an investment in each trading partner in terms of ICT compatibility that to outsiders might seem like an act of faith. That they were able to successfully compete for, and profit from involvement in internationally located projects would appear to vindicate their decision. However closer examination revealed that this success was less founded on faith and more upon a careful matching of business opportunity to the capabilities of the firm.

Although this research was not originally designed to specifically probe the issue of dynamic capabilities it became apparent during data analysis that there were obvious links between the outcomes of senior management reflection upon its strategic planning and subsequent decision-making. Specifically they had connected: performance in previous projects (the need to produce and transmit more accurate information/the development of a zero-error culture within the firm); the recognition that ICT provided the tools to achieve this, but that it required the willing cooperation of its supply-side trading partners; the recognition that acceptable levels of supply chain integration would require a considerable investment of both time and money in order to train these trading partners to exchange information to an acceptable level; and finally, that this was ultimately an exercise in changing the culture of its entire supply-side chain. It seems reasonable to conclude that these outcomes were redolent of the exercise of the focal company's dynamic capabilities.

Finally, given the foregoing this research raises some intriguing questions. Firstly, did the firm's regional location trigger the development of its dynamic capabilities, or was due to the market in which it operated? Secondly, was the cultural change that the specialist subcontractor triggered within the project described in this research a manifestation of one of its dynamic capabilities (i.e. supply chain relationship management) or was it merely a fortuitous coincidence?

\section{References}

Ajzen, I. (1991) 'The theory of planned behaviour', Organizational Behaviour and Human Decision Processes, 50, 179-211.

Archer, M.S. (2004) Culture and Agency: The Place of Culture in Social Theory, Revised Edition, Cambridge: Cambridge University Press.

Atkin, B. (1999) 'Measuring information integration in project teams', Paper presented at the CIB-W78 Workshop, Vancouver.

Boekema,F., Morgan, K. Bakkers, S. \& Rutten, R. (eds) (2000) Knowledge, innovation and economic growth: the theory and practice of learning regions, Edward Elgar publishing. Cheltenham, UK. 
Brewer, G., \& Runeson, G. (2009) 'Innovation and attitude: mapping the profile of ICT decision-makers in architectural, engineering and construction firms', International Journal of Managing Projects in Business, (3).

Brewer, G. \& Gajendran, J. (2012) 'Attitudes, behaviours and the transmission of cultural traits: impacts on ICT/BIM use in a project team', The Journal of Construction Innovation, Information Process Management, 12 (2)

Brewer, G. and T. Gajendran (2006) Picturing success: critical success factors for ICT integration in the Australian construction industry, Brisbane, Icon.Net Pty Ltd.

Brewer G., Gajendran T., \& Beard, C. (2009) 'Inhibitors to the adoption of BPM/BIM: an Australian perspective', CIBW78 Information Communication Technology in Construction Conference, Istanbul Technical University, Turkey.

Burgess, R. (1982) Field research: a source book and field manual, London, Allen and Unwin.

Davidsson, P. (1995) Culture, structure and regional levels of entrepreneurship. Entrepreneurship \& Regional Development: An International Journal Volume 7, Issue 1 pp41-62

Department of Trade and Industry (2001) Foresight: constructing the future, London, UK, DTI.

Eastman, C., Teicholz, P., Sacks, R. and Liston, K. (2008) BIM Handbook: A Guide to Building Information Modelling for Owners, Managers, Designers, Engineers, and Contractors, John Wiley \& Sons, Inc., Hoboken, NJ, USA.

Egan, J. (1998) Rethinking construction, London: DETR.

Ford, D., Ed. (1997) Understanding business markets: Interaction, relationships and networks, London, Dryden Press.

Gajendran, T., Brewer, G., \& Chen, S. (2005) 'Project teams and ICT: Surfacing the critical success factors', Paper presented at the CIBW78 Information Communication Technology in Construction, Dresden.

Gajendran, T. and G. Brewer (2007) 'Integration of information and communication technology - influence of the cultural environment', Engineering, Construction and Architectural Management, 14 (6), 532-549.

Gann, D. and A. Salter (2000) 'Innovation in project-based, service-enhanced firms: The construction of complex products and systems', Research Policy, 29, 955-972.

Geertz, C. (1966) 'Religion as a Cultural System', in M. Banton (ed.), Anthropological Approaches to the Study of Religion, New York. Praeger, 1-46.

Glaser, B. and A. Strauss (1967) Discovery of grounded theory: Strategies for qualitative research, Mill Valley, CA, Sociology Press.

Hakansson, H. and J. Johanson (1992) 'A model of industrial networks', Industrial networks: A new view of reality, B. Axelsson and G. Easton. London, Routledge.

Heertje, A. (2006) Schumpeter on the economics of innovation and the development of capitalism, Cheltenham, UK: Edward Elgar Publishing.

Khalfan, M., Asad, S., \& McDermott, P. (2007) 'Introducing innovative procurement methods for supply chain integration - implementing the challenge', Paper presented at the CIB W92 Procurement Systems Conference.

Livesey, C. (2003) 'A' Level sociology: A resource-based learning approach. Module One: Theory and methods: Unit M13: Research considerations', from www.sociology.org.uk.

Manley, K., \& McFallan, S. (2003) 'Innovation adoption behaviour in the construction sector: The case of the Queensland road industry', Paper presented at the 2nd International 
Conference on Innovation in Architecture, Engineering and Construction. Brisbane.

Martin, J., Frost, P. J., and O'Neill, O. A. (2004) 'Organizational culture: Beyond struggles for intellectual dominance', Stamford Research Paper Series, No 1864.

Morse, J. and L. Richards (2002) Readme first: for a users guide to qualitative methods, London, Sage.

Moulaert, F. \& Sekia, F. (2003) 'Territorial Innovation Models: A Critical Survey', Regional Studies, 37 (3), 289-302.

Rogers, M (1998) The Definition and Measurement of Innovation, Melbourne Institute of Applied Economic and Social Research, The University of Melbourne, Melbourne.

Rousseau, D. M. (1990) 'Assessing Organizational Culture: The Case for Multiple Methods', In I. L. Goldstein (Ed.), Frontiers of Industrial and Organizational Psychology. California: Jossey-Bass Inc.

Sakal, M. (2005) 'Project alliancing: A relational contracting mechanism for dynamic projects', Lean Construction Journal, 2 (1), 67-79.

Schein, E. H. (2004) Organizational culture and leadership, San Francisco: Jossey-Bass.

Simon, H. (1991) 'Bounded rationality and organisational learning', Organisation Science 2 (1), 17-27.

Sperber, D. (1996) Explaining culture: A naturalistic approach, Oxford: Blackwell.

Strauss, A. and J. Corbin (1990) Basics of qualitative research: Grounded theory procedures and techniques, Newbury Park, Sage.

Teece, D. (2011) 'Dynamic capabilities: a guide for managers', Ivey Business Journal, Viewed online at https://www.iveycases.com/ProductView.aspx?id=48342 on 11/02/2012.

Teece, D. J. (2010) 'Technological Innovation and the Theory of the Firm: The Role of Enterprise-level Knowledge, Complementarities, and (Dynamic) Capabilities', In N. Rosenberg and B. Hall (eds.) Handbook of the Economics of Innovation, Volume 1. Amsterdam: North-Holland.

Teece, D., Pisano, G. \& Shuen, A. (1997) 'Dynamic capabilities and strategic management', Strategic Management Journal, 18 (7) (Aug), 509-533.

Teece, D. \& Pisano, G. (1994) The dynamic capabilities of firms: an introduction. Working paper WP-94-103 International Institute for Applied Systems Analysis A-2361 Laxenburg Austria.

Venkatesh, V., M. Morris, et al. (2003) 'User acceptance of information technology: Towards a unified view', MIS Quarterly, 27 (3), 425-478.

Wasserman, S. and K. Faust (1994) Social network analysis: Methods and applications, Cambridge, UK, Cambridge University Press.

Weisberg, S. (2001) i-collaboration - State of the industry. CADALYST Magazine Retrieved 21/9/2001, from http://209.208.199.147:85//features/0901icollab/0901icolab.htm

Willmott, R. (2000) 'The place of culture in organization theory: Introducing the morphogenetic approach', Organization, 7 (1), 95-128.

Winter, S.G.(2002) Understanding Dynamic Capabilities, Working Paper WP 2002-05. The Reginald H. Jones Center, The Wharton School, University of Pennsylvania. 